\title{
JEWELLERY DESIGN AND WEARABLE APPLICATIONS: A DESIGN THINKING APPROACH
}

\author{
Athanasios Manavis $^{1}$ (D), loanna Nazlidou ${ }^{1}$ (D), Tatjana Spahiu $^{2}$ (D), Panagiotis Kyratsis ${ }^{1}$ (D) \\ ${ }^{1}$ University of Western Macedonia, Department of Product and Systems Design Engineering, \\ Kila Kozani, Greece \\ ${ }^{2}$ Polytechnic University of Tirana, Department of Textile and Fashion, Tirana, Albania
}

\begin{abstract}
The present paper examines the application of a holistic product design approach from the Design Thinking point of view. The Design Thinking process follows a number of steps with an aim to develop product design visual concepts around users' experiences and their needs. The presented case study is focused to the modern jewellery design era. The proposed design was developed by using a series of design thinking methodologies (empathy maps, persona, product design) and creative tools (mind-maps, moodboards, sketches, storyboards, and prototyping). Furthermore, through this holistic design approach an alternative version of future jewelries is achieved, while at the same time it embodies novel technologies and web-based applications. The paper discusses the potentials for reimagining the jewellery products in relation to the Design Thinking Process and CAD-based tools at the same time. Finally, the proposed products provide a novel framework of art and new technology methods for extensive production of innovative art-based products.
\end{abstract}

Key words: wearable design, Jewellery design, Computer Aided Design, design thinking tools

\section{INTRODUCTION}

Jewelleries are widely recognised as aesthetic and appealing objects that are used for personal adornment responding to customers desires. Usually wearable applications are meaningful, sophisticated iconic pieces that share a special connection with the ending users (Wilde and Marti, 2018). Based on designers' point of view, jewellery design has always been a great and interesting field for geometry form experimentation. Additionally, as technology grows rapidly there is a need for different theoretical aspects to inform new conceptual approaches in the modern jewellery design era. In that direction there is a growing challenge for all designers to consider the role and expanding capabilities of technology for innovative design in the future (Corti, 2003). An opportunity lies in the prospect to re-examine terms like wearable design, digital jewellery, interactive materiality, and embodied technologies. The term of wearability itself, implies an interaction between the human body and the object. Furthermore, the valuable aspect of any wearable products is the sensory interaction (Gemperle et al, 1998). The proposed methodology that includes design thinking, creativity and CAD based tools offers a great number of opportunities for product design development through new perspectives that could stimulate and provoke emotional responses from ending users. Certainly, the proposed research tries to conceptualize the way human experience is integrated into the design process.

\section{LITERATURE SURVEY}

Design Thinking is a non-linear iterative activity that is implicit in the process of design, involving five distinguish phases: empathize, define, ideate, prototype and test (Brondy and Kazmierczak, 2017). Design Thinking is a creative methodology used to understand users, redefine problems and create innovative solutions. Furthermore, design thinking process involves the ability to synthesize knowledge from variety of sources - an ideal tool in a holistic product design approach.

Conceptual Product Design is perceived mainly as an art than an actual science. According to Kyratsis et al., the core of Conceptual Product Design methodology is based on the design thinking principles (Kyratsis et al, 2019). The creativity process followed by a number of product designers incorporates several sessions of creative processes similar to design thinking tools (i.e. mind map, mood board, sketching, storyboard, and prototyping) with an aim to find alternative ideas for each product (Malea et al, 2020). Mind map is a graphical representation of words and phrases that are placed hierarchically based on associative logic (Buisine et al, 2007). Mood boards mostly recognised as an artistic and abstract way for expressing intangible emotions and situations through stimulating image collages (McDonagh et al, 2002). 
Furthermore, mood boards can be used by designers to communicate their vision beyond linguistic restrictions (Lucero, 2012). As well, a storyboard is used as a visual scrip of sequencing images and graphics to depict the functional aspects of the final product and the interaction with the user (Van der Lelie et al, 2006). Moreover, storyboards support product designers in getting a grip on context and time by forcing them to attend to diverse aspects, integrate these aspects and confront the implications that could be postponed with abstract considerations (Van der Lelie et al, 2006). Sketching and prototyping are flexible tools used in the early stages of the design process that allows to explore in depth a large quantity of different concepts (Qifang et al, 2018). Certainly, the act of prototyping helps designers to better understand physical characteristics of the product like form, function, and construction (Isa et al, 2015).

In holistic product design development field CAD software is a powerful tool to generate information to create three-dimensional products within a digital framework process sequence. Although the main purpose is suitability to manufacture, it is also appropriable to visualization purposes: it allows the designer to anticipate products' final look (Barros et al, 2010).

Traditional jewellery design is an art with a history of thousands of years. Only recently, the tools have changed. One way to realize a meta design today is as an executable computer program (Schinko et al, 2012). Nowadays, the boundaries of jewellery design have been continually redefined. New technologies, innovative design concepts and modern materials have overturned the notions of status traditionally implicit in jewellery (Tzintzi et al, 2017).

\section{PROPOSED METHODOLOGY}

The research presents a design case study from the holistic product development point of view. The proposed case study presents a design of a future wearable application with jewellery characteristics. The creation of the suggested application was developed by following the steps of the Design Thinking methodology based on Creativity and CAD-based tools. Furthermore, the designers examined the procedure by using information from ending users' experiences and their needs.

\begin{tabular}{|c|c|c|}
\hline \multicolumn{3}{|c|}{ The proposed design methodology } \\
\hline \multicolumn{3}{|c|}{ Stage 01 - Design Thinking tools } \\
\hline \multirow{3}{*}{$V$} & Empathy Map & Target audience \\
\hline & Persona & Fictional character \\
\hline & Product Canvas & Product details \\
\hline \multicolumn{3}{|c|}{ Stage 02 - Creativity tools } \\
\hline \multirow{4}{*}{$V$} & Mind Map & Idea exploration \\
\hline & Mood Board & Idea visualization \\
\hline & Sketching & Concept representation \\
\hline & Story Board & Concept evaluation \\
\hline 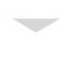 & Prototyping & User experience \\
\hline \multicolumn{3}{|c|}{ Stage 03 - CAD based tools } \\
\hline \multirow{3}{*}{$V$} & Computer-aided design modelling & Technical design approach \\
\hline & Rendering synthesis & Aesthetic design approach \\
\hline & Product visualization & Holistic design approach \\
\hline
\end{tabular}

Figure 1: The proposed design methodology

The proposed design methodology involves three crucial stages (Figure 1). First stage is a Design Thinking toolkit that it focuses to user's examination. The exploration of user's profile needs, and aspirations have become a significant part in the design thinking process. The basic tools that were used by designers are empathy maps, persona creation and product canvas. Specifically, empathy map refers to actual persons and works as a guide tool for a more descriptive analysis of the persona's mindset and needs (Ferreira et 
al, 2015). Unlike, empathy map, person creation tool do not refer to an actual user or customer, but it describes a mentality and behaviour that help designers to develop an intimate and internalized understanding of the product's audience (Guo et al, 2011). Product canvas is an organised visual chart of the most significant aspects of the product in relation to the target group needs (Pichler, 2013).

At the second stage, designers use a great number of creativity tools (i.e. mind map, mood board, sketching, storyboard, and prototype) to explore and visualize the final concept of product. All inspiration tools were used as creative techniques in order to explore the range of different ideas and concepts.

Certainly, third stage involves Computer-aided Design tools and methodologies upon to creation of final design for proposed product. The proposed product designed from technical and aesthetic design approach (CAD-based modelling, rendering synthesis and product visualization). Computer aided design is proved to be a key factor in exploring and representing much more complex forms and a helpful way for designers to better communicate their ideas.

The methodology that it is described, offers a great number of advantages to product development due to the holistic approach that involves the ending user and his needs. Finally, the suggested products provide a novel framework of art and new technology methods for extensive production of innovative art-based products.

\section{CASE STUDY - WEARABLE APPLICATION}

The first step of this research was an attempt on an in-depth knowledge of potential user's profiles. Through the empathy map tool, a research has been conducted by interviewing three different types of women. Figure 2 shows an organized template that it was created for this purpose. Empathy map questionnaires were included general guiding questions about women's feelings, thoughts, fears, concerns, behaviours, goals and hopes, in order to discover possible fields in design space for new products. The persona that came up from the combination of empathy maps refers to a woman (Zoe). Zoe is about forty years old, married with two children. Furthermore, the fictional persona of Zoe is described as an active and creative person, with an intense daily life with many obligations. Zoe enjoys travelling and contact with nature, but she feels anxious because the lack of time she does not manage to do the things she wants. In the followed product canvas board, were firstly recorded some basic characteristics of a potential product that emerged from this stage. The product canvas included requirements about the product's main goal, and its special features (i.e. time sensor, wearable gadget ad jewellery).

\begin{tabular}{|c|c|c|}
\hline \multicolumn{3}{|c|}{ Design Thinking Tools } \\
\hline \multicolumn{3}{|c|}{ Empathy Map } \\
\hline \multicolumn{2}{|c|}{ Potential user's profiles } & Questions about \\
\hline \multicolumn{2}{|c|}{ Potential user 1} & \multirow{3}{*}{$\begin{array}{c}\text { Feelings - Thoughts } \\
\text { Fears - Concerns } \\
\text { Behaviours - Goals } \\
\text { Hopes }\end{array}$} \\
\hline \multicolumn{2}{|c|}{ Potential user 2} & \\
\hline \multicolumn{2}{|c|}{ Potential user 3} & \\
\hline \multicolumn{3}{|c|}{ Persona } \\
\hline \multicolumn{2}{|c|}{ Persona ID } & Personality characteristics \\
\hline & $\begin{array}{l}\text { Zoe } \\
40 \text { years old } \\
\text { Married } \\
\text { Two children }\end{array}$ & $\begin{array}{l}\text { Active and creative } \\
\text { Intense daily life } \\
\text { Enjoy travelling } \\
\text { Contact with nature }\end{array}$ \\
\hline \multicolumn{3}{|c|}{ Product Canvas } \\
\hline \multicolumn{2}{|c|}{ Product ID } & Product characteristics \\
\hline & $\begin{array}{l}\text { Time Sensor } \\
\text { Wearable gadget } \\
\text { Jewellery }\end{array}$ & $\begin{array}{l}\text { Nature based morphology } \\
\text { Hi-tech and smart material } \\
\text { Smooth surface texture } \\
\text { User's sense of time interaction }\end{array}$ \\
\hline
\end{tabular}

Figure 2: Design Thinking tools for jewellery design and wearable application 


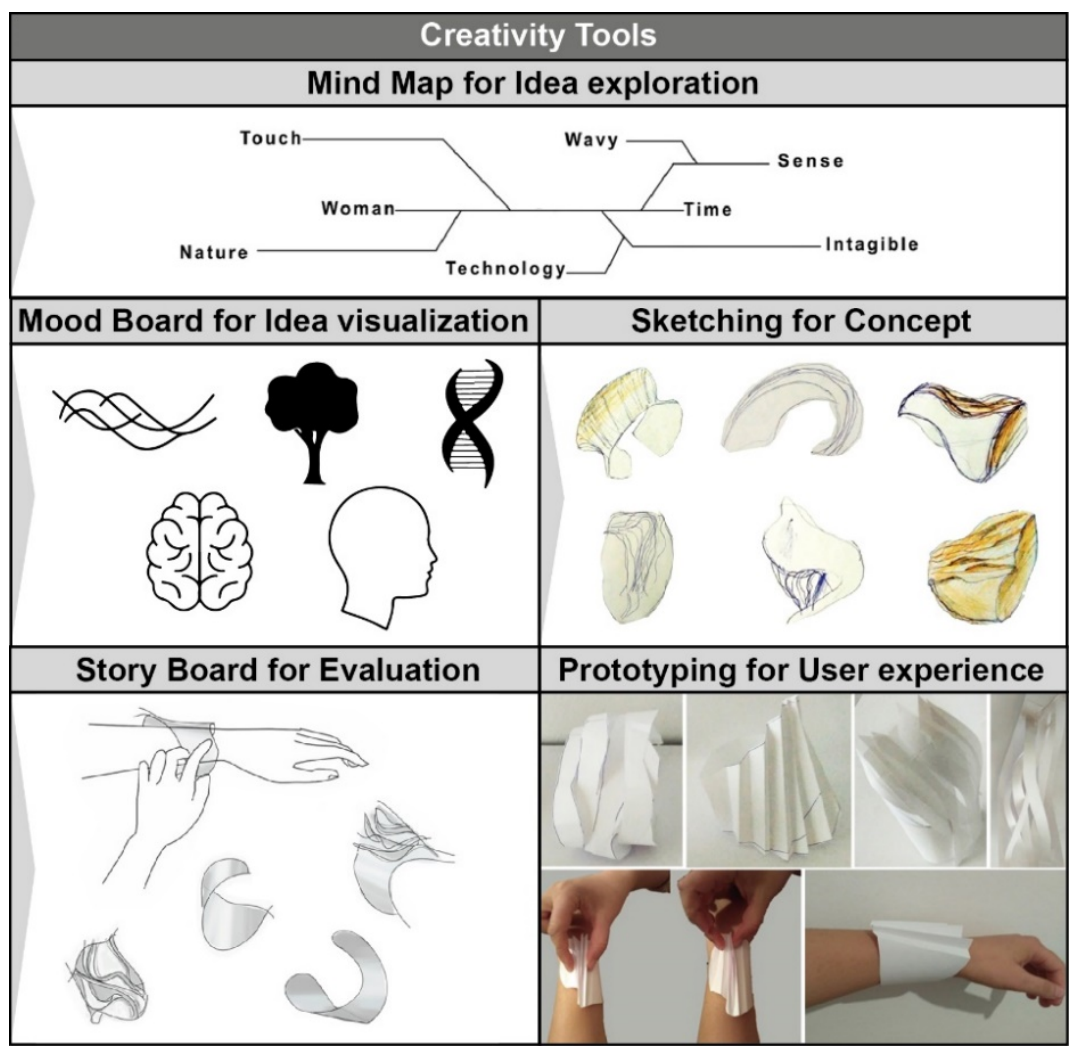

Figure 3: Creativity tools for jewellery design and wearable applications

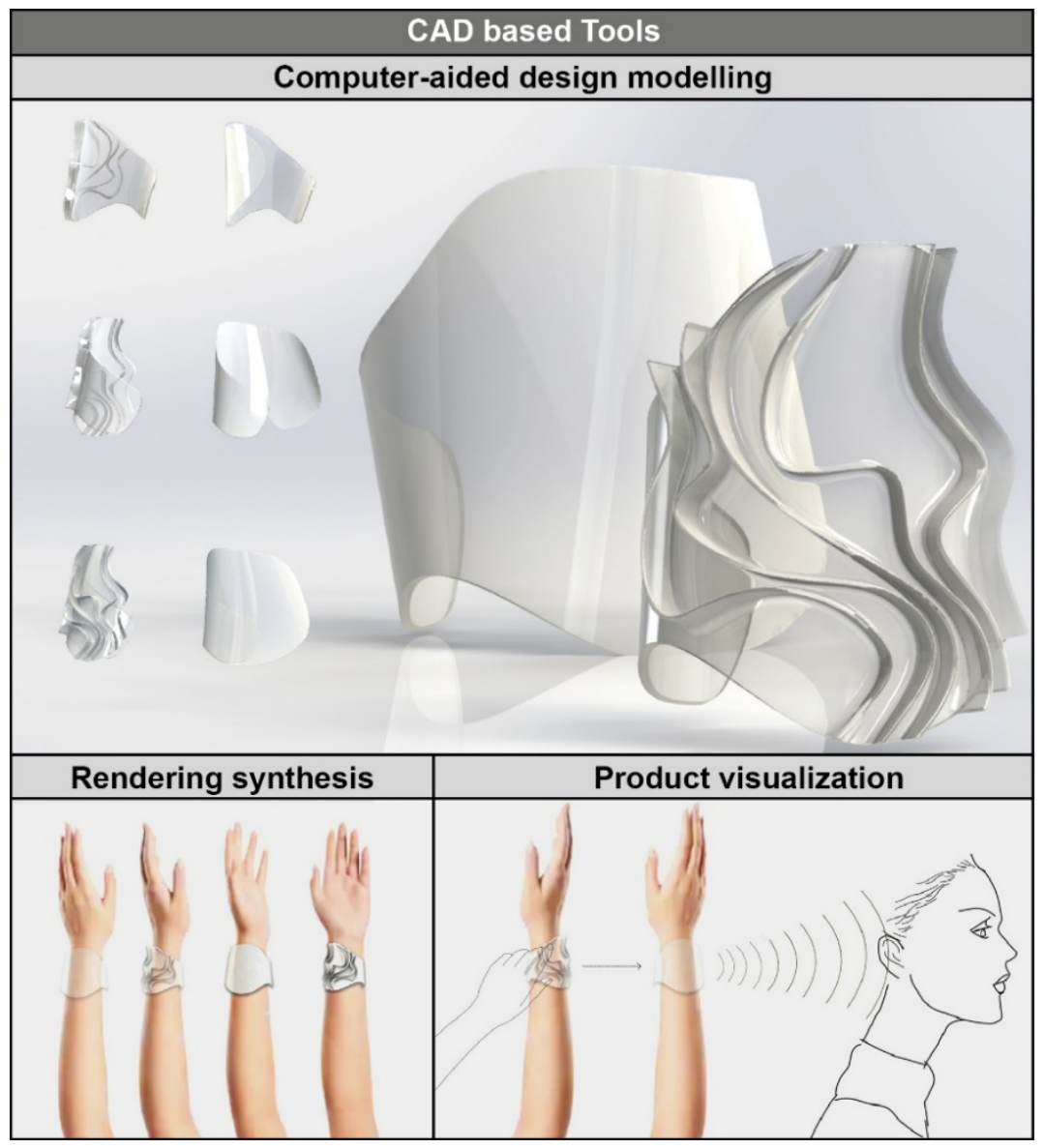

Figure 4: CAD based tools for jewellery design and wearable applications 
Second stage involves a further development of the graphical design procedure through creativity tools. Figure 3 shows the illustrative results from idea exploration tool (mind map), idea visualization tool (mood board), concept representation tool (mood board), concept evaluation tool (story board) and user experience tool (prototyping). Mind map keywords describe the main targets of the design direction, i.e. woman, time, nature, sense, and technology. Mood board visualise the keywords from mind map tool, i.e. shapes from nature and human geometries. The next step of this study is the investigation of the morphological features of the object under design. Based on the design requirements that are included in product canvas. Conceptual sketching stage illustrates the exploration of different structural concepts and the inspiration drawn by nature. Storyboard and prototyping stages include primitive prototypes of wearable application. Prototypes are made by cardboard. Figure 4 shows the final rendered versions of CAD-based models of time sensor. The final product that emerged from the Design thinking process was developed around the idea of the user interacting with time. It is an alternative version of wearable jewellery with embodied special web-based technologies, that works as a time sensor device. When the human wears the product will have the feeling through the touch that he can affect the way time passes and this could act as an anxiolytic factor in an intense daily life. The morphology of the object imitates free organic forms, enhancing a relation with nature and not giving the feeling of a latest technological device. The created product finally responds to a futuristic design logic that affects user's sense of time (Figure 5).

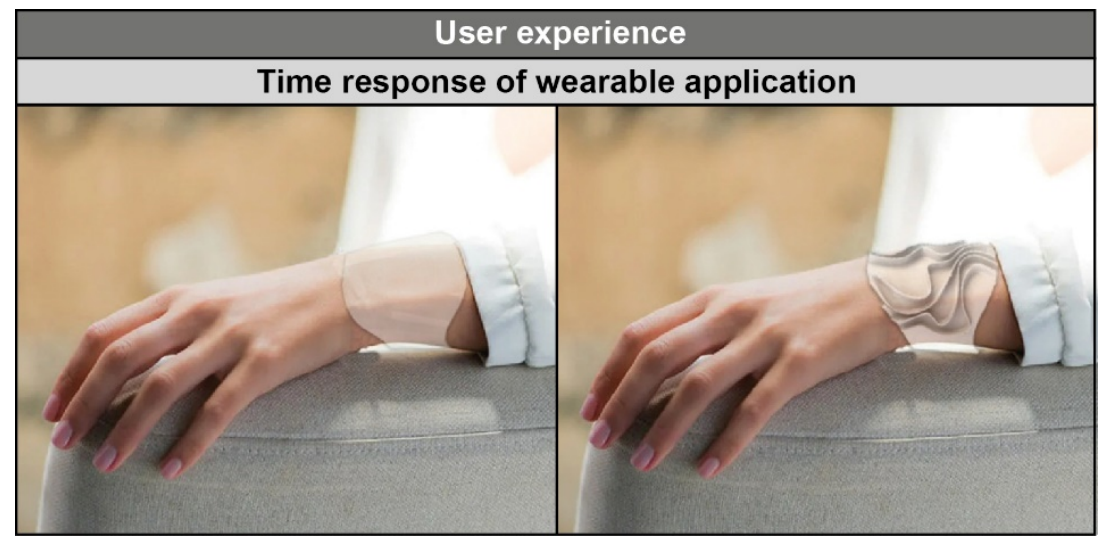

Figure 5: Time sensor based on futuristic design concept

\section{CONCLUSIONS}

The present paper examines the Design Thinking process in an attempt to reconsider a piece of jewellery not only as a luxurious accessory but as an innovative product that was created based on user's deepest needs and expectations. The research examines the aspect of wearability as an interactive relationship between the human body and the designed product. The main core of the concept was to redefine the user's relationship with time. The proposed methodology that includes design thinking, creativity and CAD based tools could offer a series of great design and marketing advantages to designers that would be willing this design procedure. Furthermore, the presented design approach based on design thinking principles, incorporate not only innovative creative design, but the creation of novel futuristic wearable applications. Certainly, the proposed design development approach tries to conceptualize the way human experience is integrated into the design process.

\section{REFERENCES}

[1] Barros, M.: "The Role of Different CAD Applications in Product Design Teaching", Proceedings of $5^{\text {th }}$ International Conference on Digital Arts - Artech 2010, (Minho University, Braga, Portugal, 2010), pages 197-200.

[2] Brondy, J., Kazmierczak, J.: "The design thinking method and its stages", Wspomagaania W Inzynierii Produkcji, 6, 247-255, 2017. 
[3] Buisine, S., Besacier, G., Najm, M., Aoussat, A., Vernier, F.: “Computer-Supported Creativity: Evaluation of a Tabletop Mind-Map Application", Proceedings of Engineering Psychology and Cognitive Ergonomics, $7^{\text {th }}$ International Conference EPCE 2007, (Springer, Berlin, Heidelberg, 2007), pages 22-31.

[4] Corti, C.W.: "Technology is irrelevant to Jewellery Design-or is it?", Proceedings of The Santa Fe Symposium on Jewelry Manufacturing Technology 2003, pages 15-28.

[5] Ferreira, B., Silva, W., Oliveira, E., Conte, T.: "Designing Personas with Empathy Map", Proceedings of The $27^{\text {th }}$ International Conference on Software Engineering and Knowledge Engineering, SEKE 2015, (KSI Research Inc., Pittsburgh, USA, 2015), pages 501-505.

[6] Gemperle, F., Kasabach, C., Stivoric, J., Bauer, M., Martin, R.: "Design for Wearability", Proceedings of Digest of Papers. Second International Symposium on Wearable Computers 1998, (IEEE, Pittsburgh - USA, 1998), pages 116-122.

[7] Guo, F.Y., Shamdasani, S., Randall, B.: "Creating Effective Personas for Product Design: Insights from a Case Study", Proceedings of $4^{\text {th }}$ International Conference IDGD: International Conference on Internationalization, Design and Global Development (Orlando, FL USA, 2011), pages 37-46.

[8] Isa, S.S., Liem, A., Steinert, M.: "The value of prototypes in the early design and development process", Proceedings of the ICED15 (Milan, Italy, 2015), pages 235-242.

[9] Kyratsis, P., Manavis, A., Gianniotis, P., Ghiculescu, L.D.: "A non-conventional methodology for interior product design using conceptual design principles and parametric tools", Nonconventional Technologies Review 23, 16-21, 2019.

[10] Lucero, A.: "Framing, Aligning, Paradoxing, Abstracting, and Directing: How Design Mood Boards Work", DIS 2012 (In the Wild, Newcastle, UK, 2012), pages 438-447.

[11] Malea, A., Tzotzis, A., Manavis, A., Kyratsis, P.: "Innovative and sustainable toothpaste packaging design", Journal of Graphic Engineering and Design 11, 19, 2020. doi: 10.24867/JGED-2020-2-019.

[12] McDonagh, D., Bruseberg, A., Haslam, C.: "Visual product evaluation: exploring users' emotional relationships with products", Applied Ergonomics 33, 231-240, 2002. doi: 10.1016/S00036870(02)00008-X.

[13] Pichler, R.: "The Product Canvas - A Lean Tool for Creating New products", Cambridge Product Management Network, 2013.

[14] Qifang, B., Faas, D., Yang, M.: "Interplay of sketching \& prototyping in early stage product design", International Journal of Design Creativity and Innovation 6, 146-168, 2018. doi: 10.1080/21650349.2018.1429318.

[15] Schinko, C., Berndt, R., Krispel, U., Settgast, V., Havemann, S., Eggeling, E., Fellner, W.D.: "Ring's Anatomy - Parametric Design of Wedding", Proceedings of CONTENT 2012, (Xpert Publishing Services, Wilmington, USA 2012), pages 72-78.

[16] Tzintzi, V., Manavis, A., Efkolidis, N., Dimopoulos, C., Kakoulis, K., Kyratsis, P.: "Conceptual design of jewellery: a space-based aesthetic approach", Proceedings of the $21^{\text {th }}$ Innovative Manufacturing Engineering and Energy Conference 2017, (IManEE, Romania 2017).

[17] Van der Lelie, C.: "The value of storyboards in the product design process", Personal and Ubiquitous Computing 10, 159-162, 2006. doi: 10.1007/s00779-005-0026-7.

[18] Wilde, D, Marti, P.: "Exploring Aesthetic Enhancement of Wearable Technologies for Deaf Women", Designing Interactive Systems (DIS) (Hong Kong, 2018), pages 201-213.

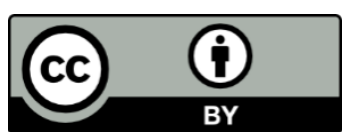

(C) 2020 Authors. Published by the University of Novi Sad, Faculty of Technical Sciences, Department of Graphic Engineering and Design. This article is an open access article distributed under the terms and conditions of the Creative Commons Attribution license 3.0 Serbia (http://creativecommons.org/licenses/by/3.0/rs/). 